REVIEW

\title{
"Contact A Family": professionals and parents in partnership
}

S Davies, D Hall

Arch Dis Child 2005;90:1053-1057. doi: 10.1136/adc.2004.070706

This paper considers the evidence base on the role of parent organisations in meeting the needs of parents of disabled children for information and support. Having a disabled child is a major cause of stress and has an impact on the health and wellbeing of the entire family. Current concepts of stress and coping are used to consider coping strategies, including the search for information, the desire to stay in control, and the quest for social support. How and when information and support are provided will impact on how well the family adjust and cope.

See end of article for authors' affiliations

.....................

Correspondence to: $S$ Davies, Contact A Family, 209-11 City Road, London ECIV 1JN, UK; Sheila.davies@cafamily. org.uk

Accepted 20 May 2005
। n 1978 Dame Mary Warnock wrote “...the successful education of children with special educational needs is dependent upon the full involvement of their parents; indeed, unless the parents are seen as equal partners in the educational process the purpose of our report will be frustrated". ${ }^{1}$ The concept of partnership between professionals and the parents of children with disabilities or special needs has been endorsed in many subsequent reports. ${ }^{2-5}$

In 2004, a joint project called "Parents and Paediatricians Together" (see box 1) was launched by Contact A Family and the Royal College of Paediatrics and Child Health (RCPCH). The early stages of the project have revealed a number of professional concerns about the role of parent organisations, and the impact of their information and support on parents who have to cope with the diagnosis of a disability in their child. In this paper we summarise current concepts of stress and coping and then ask "what is the evidence base on the contribution of parent organisations in meeting the needs of parents?". We searched Medline, Assia, Cinahl, Bni, Embase, Web of Science, and the Internet (using Google Scholar), for articles on parent self-help or support groups, in relation to information, disability or empowerment.

\section{DISABILITY, STRESS, AND COPING}

Research on parental reactions to disability consistently reveals two themes. The first is to do with parents' memories and perceptions of how they received the diagnosis. They remember two main aspects of news-breaking-the personal qualities and empathy of the professionals who told them about their child's disability, and the quality and quantity of information and support provided. ${ }^{6}$ The second theme is that caring for a disabled child often causes stress for the entire family. The daily toil of care, frequent hospital and clinic visits, sleep disturbance, and financial pressures all take their toll. $^{78}$ Challenging behaviours cause public embarrassment. ${ }^{9}$ Exhausted parents have little time for each other or for siblings, so family relationships suffer. Parents often feel isolated, lonely, and unsupported.

Beresford $^{10}$ has reviewed the Lazarus and Folkman ${ }^{11}$ model of stress and coping mechanisms and shown how this applies to disabled children (fig 1). She emphasises that coping is a process, since many problems, like having a disabled child, can be managed but not mastered or overcome. The model incorporates the concept of "appraisal" which is the process of considering and interpreting a potentially stressful situation. Many factors influence this appraisal. Coping is a mobilisation of efforts and resources, to manage the demands made on the individual(s) by the situation. The search for information that will facilitate the process of appraisal, and the need for various forms of support, are intrinsic to this model. Parents need information so that they can make decisions for themselves and their child, take control of the situation, and access support. How and when information and support are provided is likely to impact on how well the family adjust and cope.

\section{Information seeking}

This is a positive coping strategy. Information facilitates the processes of appraisal and adjustment; it enables parents to manage their child's condition and judge what would maximise their child's potential future, giving them more control over their present and future family life; and it enables them to access services and benefits.

Struggling to find information can leave parents feeling anxious, confused, and alienated from others. Poorly timed, incomprehensible information makes them frightened and disempowered. Health professionals need to convey information in a way the parent can understand. ${ }^{12}$ In general, information should be covered verbally first and written material used as a back up: $:^{12}$

\footnotetext{
"You need them to tell you but when you go away, quite often you've forgotten everything they've said, so if it's written down on a piece of paper as well, exactly what they've said to you, then you can go back and when you've got 5 minutes to spare you can read it and then you remember it." (Parent) ${ }^{12}$
} 


\section{Box 1: Contact A Family}

"Contact A Family" began in 1974 as a community initiative in the London borough of Wandsworth, with the aim of encouraging mutual support between families of children with disabilities. It grew into a national charity whose ethos is to empower parents to help themselves. It provides medical information to parents of children with any disabling medical condition via its directory (www.cafamily.org.uk) and guidance on accessing social support through its free phone help line and offices. It provides details of national support groups for specific conditions and of local parent support groups and, in the case of rare conditions, endeavours to link individual families. The charity also provides advice and assistance to individuals wanting to form support groups.

The "Parents and Paediatricians Together" project is a three year joint project between Contact A Family and the Royal College of Paediatrics and Child Health, funded by the Big Lottery. It aims to encourage paediatricians to help families find reliable sources of information, and to develop a closer dialogue between parents, parent organisations, and paediatricians so that parents' expertise in their child's condition can be utilised by other parents and by professionals.

\section{Parent control and the professional-patient relationship}

Professionals' attitudes to services for disabled children are gradually moving from one dominated by the "expert" paternalistic professional to an "empowerment" model. ${ }^{14-16}$ Paternalism is an attitude of mind in which the professional feels that they know what is best for the parents and so does not treat them as responsible adults and equal partners. The manner in which professionals communicate with parents can carry hidden messages, leaving the parent feeling they are not competent to take part in decision making and need to leave that to others: ${ }^{17}$

"Billy's hospital consultant doesn't call me Mrs A, but 'mum'." (Parent)

"He so obviously didn't believe that I was bright enough to study for a degree-he just saw me as a mum, living in a council house, with no brain, only able to look after children. ... when I told him about my degree he switched to thinking it must have been so hard for me to study and looked like he wanted to give me a pat on the head. I don't know which was worse!" (Parent-recently graduated with Honours degree)

By treating parents as equals, respecting their knowledge of their child, appreciating their desire to become knowledgeable of their child's condition, acknowledging the difficulties they face and being willing to engage in dialogue, professionals promote parents' sense of control. True partners use negotiation and joint decision making to reach a shared perspective or jointly agreed decisions on issues of mutual concern. ${ }^{14}$

\section{Social support and the role of support groups}

When a child is first diagnosed with a disability, the family expect the professional team to react with empathic listening, accessible information, and practical help. However, many families also look for support elsewhere, including from other parents who have had similar experiences. ${ }^{18-22}$ Isolation and a feeling of stigmatisation are common experiences of the parents of disabled children. Their lives revolve around the child. Meeting other parents creates a sense of belonging which reduces these feelings of isolation. ${ }^{23-25}$ Other parents

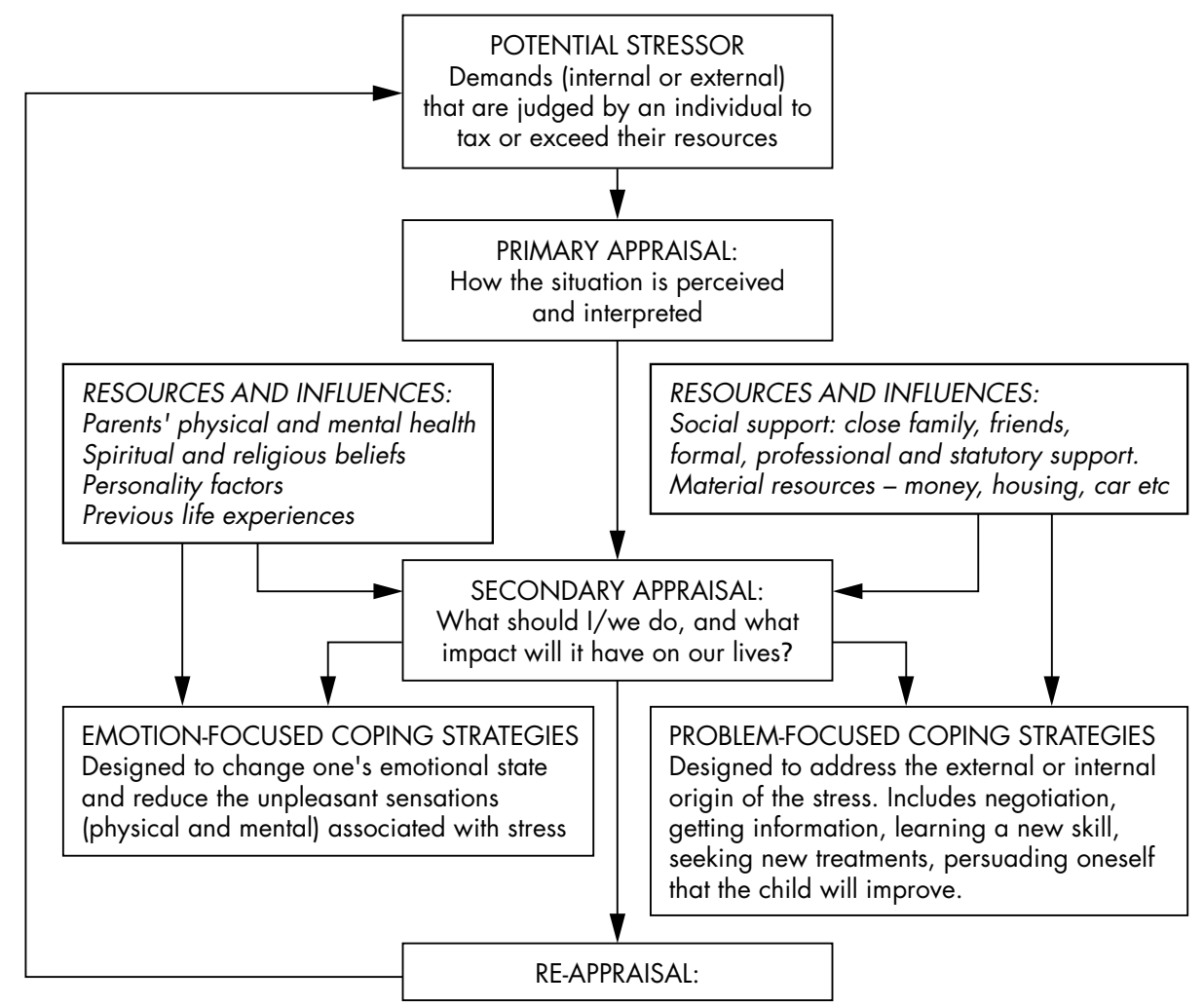

Figure 1 Stress and Coping Model, based on Lazarus and Folkman ${ }^{11}$ and Beresford ${ }^{10}$ (with permission of J Child Psychol Psychiatry). 
can also provide a credible model of how to cope in a positive way with exceptional life circumstances. ${ }^{182627}$ One parent commented that:

\section{"I finally felt like a person. I had the feeling that I belonged in a community with others in similar situations."}

Another said:

\section{"Knowing we aren't alone in experiencing this stuff makes it much easier to bear, breaking that sense of isolation and otherness."}

Although old networks may disintegrate, many families make new friends as a result of having a disabled child, through networks of people involved with disability. "Expert" parents help in the interpretation of information, both about complex medical issues and about entitlements and local services, and this is helpful when communicating with professionals: ${ }^{928}$

\section{"You see so many professionals, and they will tell you all the medical terms for everything, and you see the educational people, who give you all the jargon on what they want you to hear, but you (also) need the parents who have experienced the shortfalls in the system, or the good and bad." (Parent) ${ }^{13}$}

Parents can meet other parents through groups run by voluntary agencies, professionals, ${ }^{26} 2922$ or parents. ${ }^{30}{ }^{31}$ Some cater for just one specific condition while others are open to parents of children with a wide range of conditions. There are local groups, national groups, and local groups with national affiliations. ${ }^{18}$ In one-to-one linking, a parent of a newly diagnosed child is put in touch with a more experienced parent. In the Face 2 Face project, sponsored by SCOPE, experienced parents who have come to terms with their own child's disability are first trained in listening and counselling skills. ${ }^{32} 33$

Sharing ideas and strategies to cope with common problems increases parents' confidence and competence with benefit to their child. ${ }^{27}{ }^{30}$ Meeting other parents who are enjoying life gives hope so that the future no longer appears so bleak. Parents can share emotions, "let off steam", enjoy themselves, and laugh and share pride in their child's achievements. By having a "safe place" to express their feelings, parents find that they are calmer when liaising with professionals:

\section{"This is our lifeline, like sometimes it's the only thing that keeps you going till the next month to be able to talk to the mothers. ${ }^{\prime 30}$}

\section{"Each person has the right to express how they feel and nobody comments on the way they're expressing their frustration or problems. ${ }^{\prime \prime 30}$}

"I've vented my anger here, shown my tears, and if I hadn't have let them out here I would probably have killed the children. ${ }^{\prime \prime 31}$

The progression from "receiving" information and support, to "providing" it helps parents to feel valued and to turn their stressful life experiences to good use. ${ }^{3134}$ Indeed, some parents make a valuable contribution to professional education..$^{35}$

\section{ARE THERE ANY PROBLEMS WITH PARENT GROUPS?}

In the last five years Contact A Family has received over 25000 enquiries from families wanting to make contact with other families, so clearly this is important to many parents; nevertheless, most of the literature is based on findings from parents who were members of groups, so the benefits are likely to have been emphasised and any negative effects under-reported. Concerns about possible negative effects were expressed by a few paediatricians involved in the early stages of the Contact A Family/RCPCH project.

One key question was the extent to which parents need to be "matched" in order to minimise harm and maximise benefits. Parents' anxieties might be raised if they met with families whose child was more severely affected than their own. This issue is probably more sensitive in the case of one to one linkages than for larger groups. Singer and colleagues' evaluation of parent to parent support showed $89 \%$ parents found it helpful. ${ }^{37}$ The $11 \%$ who did not perceived a difference between the parents and the support parents. This was not merely a question of "matching" children for condition and severity-social class, ethnicity, career ambitions, and lifestyle contribute to the success or otherwise of such a relationship, and perhaps what matters most is the perceived sameness of the matched families. ${ }^{38}$

Many parents find meeting people whose child's difficulties are greater than their own helps them put their own problems into perspective. ${ }^{23}$ Folkman and Lazarus suggested that "an ambiguous state of affairs (may be) more stressful than knowing even the most negative outcome". ${ }^{39}$ Families who are coping well and getting on with their lives can give parents confidence that they too can cope. ${ }^{28}$ Nevertheless, parents could become anxious if they meet other children whose problems are very different from those of their own child, or if the extent of their child's likely future problems is revealed to be worse than they had feared: ${ }^{13}$

\section{Mother: What makes it worse is that we have an autistic relation as well. \\ Father: Yes, in some ways, because you can see what my sister's been through. You think, "we've got that to go through".}

These reactions can largely be avoided if health professionals explain the range of severity of a condition, and likely prognosis, so parents will not make assumptions that their child will be affected in the same way as another child they already know of, or might one day meet.

Other concerns expressed about parent groups include: parents getting incorrect medical information from voluntary groups; parents demanding therapies that are not available or that are thought by the professional team to be inappropriate; parents asking for referrals to other professionals perceived as having specialist expertise; meeting parents who are hostile to doctors. These are understandable fears, but professionals cannot prevent parents searching for information about their child's condition, or seeking contact with other families. The "empowerment" model presumes that professionals will assist parents to find good sources of information, help them discern what is reliable, and support them in making decisions that are right for them. This promotes a relationship between professional and parents where the parents feel comfortable in raising questions and concerns and discussing information found elsewhere. ${ }^{40}$

Is there an optimal time for parents to seek information from voluntary organisations or to join groups? The emotional "journey" involved in coming to terms with having a disabled child has been described as having a 
Box 2: Child Development Centre, Scarborough; parent groups and service providers working together

At the Child Development Centre in Scarborough a family room is made available for parent groups to meet in. The Child Health Advisory group has set up Task Groups for Disability, Autism, Surveillance, Looked after Children, and Hearing Impairment. These groups are multi-agency. Each includes a parent representative who is also a member of a Parent Group and can channel information between the Task Group and the Parent group. This promotes an ongoing two way dialogue, where parents' concerns are fed to the committee by the parent representative, and the parent representative feeds back to the group problems encountered by the committee (see hitp://www.cafamily.org.uk/ papt.html\#participation).

number of stages-shock, disbelief, anger, searching, bargaining, and acceptance. However, this does not accurately represent the experiences of all parents, who react and cope in different ways. ${ }^{14}$ Professionals who take it on themselves to judge when a parent is "ready" to use information "appropriately" are regressing into the "expert" mode, and they disempower parents in the process.

\section{A SYNTHESIS}

There has been some progress towards genuine partnerships between parents and professionals (for example, box 2), but more needs to be done-for instance, many teams are still reluctant to provide parents with written reports, notwithstanding the extensive evidence that they are valued, or to comply with the explicit requirement of the Code of Practice regarding the provision of information about voluntary organisations (box 3).

There are legitimate concerns that too much information or misguided parent organisations might be harmful but, notwithstanding the bias referred to earlier, there is persuasive evidence that the opportunity to talk to families who have had similar experiences does help parents feel less isolated ${ }^{41}$ more accepting of themselves, more self-confident, more valued by others, and better informed and equipped to cope with everyday issues. The evidence also shows that written material should be available as follows for all parents of newly diagnosed disabled children: ${ }^{12}$

- General information about disability and entitlements with brief summaries of local services and support alongside more informative and in-depth guides

- Detailed material on their child's condition and an account of what this means for their child

- The existence of voluntary groups (both for condition specific information and for local support) and how to find the most relevant ones

- How to assess the reliability of information (for example, rejecting out of date books or websites, checking the credentials of those who advise voluntary groups, and being aware of the wide range of severity even within specific conditions).

\section{A HYPOTHESIS}

Although the evidence in support of the "empowerment" approach is persuasive, the lack of formal prospective studies involving all new attenders at a child disability service is

\section{Box 3}

The role of voluntary agencies in the parent-professional partnership is emphasised in the 2001 Code of Practice for Special Educational Needs 5 (page 39): "Health Authorities and National Health Service (NHS) Trusts must inform the parents and the appropriate LEA... if they believe that a particular voluntary organisation is likely to be able to give the parents advice or assistance in connection with any special educational needs that the child may have" (see Section 332, Education Act 1996).

disappointing. We predict, on the basis of the literature and our experience, that if the evidence and suggestions set out here are implemented:

- Parents will use information and social support at varying times that suit them, and some will not wish to access either

- Most will make decisions that are right for them and therefore negative effects will be minimal

- Overall parent satisfaction will increase, leading to an improved relationship between families and professionals

- Parents will make more appropriate and effective use of professional expertise and Early Support services ${ }^{42}$

- This will reduce health service costs.

A prospective study is needed to test that hypothesis.

\section{ACKNOWLEDGEMENTS}

We thank the Big Lottery for funding the project described in this article; and Lucy Arnold and Lynda Ayiku for help with the literature searches.

\section{Authors' affiliations}

S Davies, Paediatric Project Officer, Contact A Family, 209-211 City Road, London ECIV IJN, UK

D M B Hall, Institute of General Practice, ScHARR, University of Sheffield; Institute of General Practice, Community Sciences Building, Northern General Hospital, Sheffield S5 7AU, UK

Competing interests: Sheila Davies is project officer for the "Parents \& Paediatricians Together " joint programme between Contact A Family and the Royal College of Paediatrics and Child Health.

\section{REFERENCES}

1 Warnock, Dame M. Special Education Needs - the Warnock Report. London: HMSO, 1978.

2 The National Services Framework for Children, Young People and Maternity Services. Disabled children and young people and those with complex health needs. London: Department for Education and Skills and Department of Health, 2004.

3 Audit Commission. Services for disabled children. London: HMSO, 2003.

4 DfES. Removing barriers to achievement: the government's strategy for special educational needs. London: Department for Education and Skills, 2004.

5 DfES. Code of Practice for Special Educational Needs. London: Department for Education and Skills, 2001.

6 Rahi J, Manaras I, Tuomainen $\mathrm{H}$, et al. Meeting the needs of parents around the time of diagnosis of disability among their children: evaluation of a novel program for information, support, and liaison by key workers. Pediatrics 2004; 1 14:e477-582.

7 Joseph Rowntree Foundation. Supporting disabled children and their families-N79. York: Joseph Rowntree Foundation, 1999.

8 Joseph Rowntree Foundation. The impact of childhood disability on family life-Report 631. York: Joseph Rowntree Foundation, 2001. Available at: http://www.jrf.org.uk/knowledge/findings/socialcare/631 asp (accessed 6 March 2005).

9 Adesida O, Foreman D. A support group for parents of children with hyperkinetic disorder: an empowerment model. Clin Child Psychol Psychiatry 1999;4:567-78.

10 Beresford BA. Resources and strategies: how parents cope with the care of a disabled child. J Child Psychol Psychiatry 1994;35:171-209. 
11 Lazarus R, Folkman S. Stress, appraisal and coping. New York: Springer, 1984.

12 Mitchell W, Sloper P. Information that informs rather than alienates families with disabled children: developing a model of good practice. Health Soc Care Community 2002;10:74-81.

13 Pain H. Coping with a child with disabilities from the parents' perspective: the function of information. Child Care Health Dev 1999;25:299-312.

14 Case S. Refocusing on the parent: what are the social issues of concern for parents of disabled children? Disability and Society 2000;15:271-92.

15 Appleton P, Minchom P. Models of parent partnership and child development centres. Child Care Health Dev 1990;17:27-38.

16 Case S. Learning to partner, disabling conflict: early indications of an improving relationship between parents and professionals with regard to service provision for children with learning disabilities. Disability and Society $2001 ; 16: 837-54$.

17 Brett J. The experience of disability from the perspective of parents of children with profound impairment: is it time for an alternative model of disability? Disability and Society 2002;17:825-43.

18 Ablon J. The parents' auxiliary of little people of America: a self-help model of social support for families of short-statured children. Prevention in Human Services 1982;1:31-46.

19 Ablon J. Parents' responses to their child's diagnosis of neurofibromatosis 1. Am J Med Genet 2000:93:136-42.

20 Aytch L, Hammond R, White C, et al. Seizures in infants and young children: an exploratory study of family experiences and needs for information and support. J Neurosci Nurs 2001;33:278-85.

21 Fisher $\mathbf{H}$. The needs of parents with chronically sick children: a literature review. J Adv Nurs 2001;36:600-7.

22 Stallard P, Dickinson F. Groups for parents of pre-school children with severe disabilities. Child Care Health Dev 1994;20:197-207.

23 Winch AE, Christoph JM. Parent-to-parent links: building networks for parents of hospitalized children. Child Health Care 1988;17:93-7.

24 Beck Black R, Weiss J. A professional partnership with genetic support groups. Am J Med Gen 1988;29:21-33.

25 King G, Stewart D, King S, et al. Organizational characteristics and issues affecting the longevity of self-help groups for parents of children with special needs. Qual Health Res 2000;10:225-41.

26 Boukydis CFZ, Moses L. Innovations in practice. Establishing and maintaining a parenting network for parents of premature/high-risk infants. Infants Young Child 1995;7:77-87.
27 Rollins JA. Self-help groups for parents. Pediatr Nurs 1987; 13:403-9.

28 Hartman AF, Radin MB, McConnell B. Parent-to-parent support: a critical component of health care services for families. Issues Compr Pediatr Nurs 1992;15:55-67.

29 Friedlander SR, Watkins CE Jr. Therapeutic aspects of support groups for parents of the mentally retarded. Int J Group Psychother 1985;35:65-78.

30 Law M, King S, Stewart D, et al. The perceived effects of parent-led support groups for parents of children with disabilities. Phys Occup Ther Pediatr 2001;21:29-48.

31 Solomon M, Pistrang N, Barker C. The benefits of mutual support groups for parents of children with disabilities. Am J Community Psychol 2001;29:113-32.

32 White C. Friendly faces. Community Care 1996;4:10.

33 SCOPE. Face to face. London: Scope, 2003. Available at: http:// www.face2facenetwork.org.uk/ (accessed 6 March 2005).

34 Kerr S, Mclntosh J. Coping when a child has a disability: exploring the impact of parent-to-parent support. Child Care Health Dev 2000;26:309-22.

35 Blasco PA, Kohen H, Shapland C. Parents-as-teachers: design and establishment of a training programme for paediatric residents. Med Educ 1999;33:695-701.

36 SCOPE. Right from the start. London: Scope, 1994. Available at: http:// rightfromthestart.org.uk/ (accessed 6 March 2005)

37 Singer $\mathrm{H}$, Marquis J, Powers $\mathrm{L}$, et al. A multi-site evaluation of parent to parent programs for parents of children with disabilities. J Early Intervention 1999;22:217-29.

38 Ainbinder JG, Blanchard LW, Singer GH, et al. A qualitative study of parent to parent support for parents of children with special needs. J Pediatr Psychol 1998;23:99-109.

39 Folkman S, Lazarus R. Coping and emotion. In: Monat A, Lazarus R, eds. Stress and coping - an anthology. New York: Columbia University Press, 1991:207-27.

40 Appleton PL, Boll V, Everett JM, et al. Beyond child development centres: care coordination for children with disabilities. Child Care Health Dev 1997;23:29-40.

41 Young M, McMenamy J, Perrin E. Parent advisory groups in pediatric practices: parents' and professionals perceptions. Arch Pediatr Adolesc Med 2001;155:692-8

42 Sure Start, Department for Education and Skills, Department of Health. Early support. http://www.earlysupport.org.uk/pilot2/index.html (accessed 26 May 2005). 